COMMENTARY ON COVID-19 AND THE FoOd SYSTEM

\title{
Food systems resilience through dialogue: Localizing a food systems approach in pandemic response
}

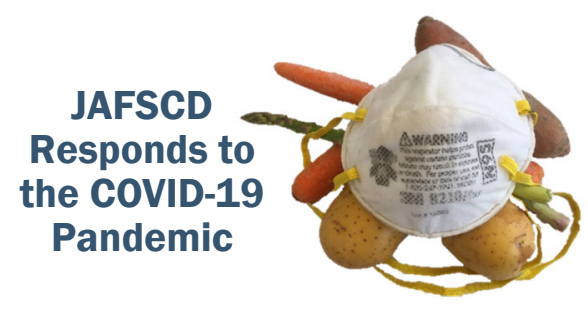

\author{
Angela R. Hansen a* \\ University of Cape Town \\ Eilif Ronning ${ }^{b}$ \\ Food Systems Foresight \\ Katie Collier ${ }^{\mathrm{c}}$ \\ University of Pennsylvania
}

Submitted October 2, 2020 / Published online December 12, 2020

Citation: Hansen, A. R., Ronning, E., \& Collier, K. (2020). Food systems resilience through dialogue:

Localizing a food systems approach in pandemic response. Journal of Agriculture, Food Systems, and

Community Development, 10(1), 265-268. https://doi.org/10.5304/jafscd.2020.101.033

Copyright (C) 2020 by the Authors. Published by the Lyson Center for Civic Agriculture and Food Systems. Open access under CC-BY license.

\begin{abstract}
Community and international development practitioners are increasingly adopting a food systems approach to research, planning, and intervention. This paper examines such an approach as part of the COVID-19 response of the Food Systems Dialogues (FSDs), a global effort facilitating multistakeholder interchange to build support for food systems transformations. The FSDs' pandemic response involved redesigning the in-person global dialogue process for online delivery in localized settings. This paper documents how the online FSDs in New York's Hudson Valley allowed local systems actors to share their experience mid-shock, as the system responded to the pandemic, and revealed FSDs' ability to quickly adopt a systems orientation and thus take the first steps toward transforming food systems. It also highlights where new research is needed in food systems approaches to development.

a * Corresponding author: Angela R. Hansen, Graduate School of Business, University of Cape Town; 9 Portswood Road, Victoria \& Alfred Waterfront; Cape Town, 8002, South Africa; +1-917-302-9715; angela.r.hansen@gmail.com

b Eilif Ronning, Food Systems Foresight; Oslo, Norway; eilif.ronning@gmail.com

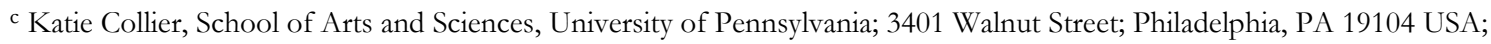
katiecollier5137@gmail.com

Acknowledgments

The authors are grateful to the participants of the Hudson Valley Online Food Systems Dialogues for their insights, the Food Bank of the Hudson Valley for its partnership, and Dr. David Nabarro for his systems leadership.
\end{abstract}




\section{Keywords}

Asset-Based, Food Governance, Food Systems Approach, Food Systems Resilience, Food Systems Transformation, Planning, COVID-19, Pandemic

\section{A Food Systems Approach}

The COVID-19 pandemic exacerbated the challenges facing food systems, including persistent food insecurity and malnutrition (HLPE, 2020). The pandemic shock necessitated both immediate interventions to combat food insecurity and long-term research and planning to build more resilient food systems for the future.

A food systems approach focuses on activities and outcomes and how they are shaped by socioeconomic drivers and environmental change (Ingram, 2011). This approach considers the elements in our food systems and the relationships between them (van Berkum, Dengerink, \& Ruben, 2018). Proponents of a food systems approach recognize that current global frameworks fail to conceptualize food systems as a unified whole and call for them to be urgently re-cast as such so that shared visions of transformation can be realized (Rosenzweig et al., 2020). Corporate shareholders and stakeholders may increasingly expect food businesses to adopt this approach as well (Hansen, Ingram, \& Midgley, 2020).

While the food systems approach has enjoyed widening acceptance, food systems analysis, which tends to involve the decomposition of systems into functions of interest, has had more limited relevance. However, a meta-analysis suggests potentially useful archetypes of inquiry (Brouwer, McDermott, \& Ruben, 2020). Brouwer et al. posit that an archetype of 'systems-oriented' inquiry demonstrates the use of dialogue to encourage the gradual evolution of norms and values (2020, p. 7). The Food System Dialogues share characteristics of this archetype, aiming to generate global consensus regarding food systems transformation in line with the 2030 Sustainable Development Agenda (Lawrence, Baker, Pulker, \& Pollard, 2019). At the local level, such dialogue can build relationships and weave together previously divergent discussions. This, in turn, can fuel food systems transformation by creating conditions for the convergence of local and global priorities (Caron et al., 2018). This was the ultimate intention of the online FSDs event series in the Hudson Valley.

\section{Application to Hudson Valley Food Systems}

New York's Hudson Valley is a vibrant agricultural region with links to both New York City and the state's capital city of Albany. Twenty-two hundred farms cover approximately $10 \%$ of the valley, which leads the state in the production of vegetables, poultry, and eggs. In addition, there is a strong local food system, evidenced by over 100 community supported agriculture farms (CSAs) that connect primary producers to consumers for direct advance sales (Hudson Valley CSA Coalition, n.d.). Despite this bounty, food insecurity was an issue in Hudson Valley prior to the pandemic, when household food assistance was utilized at levels in line with the national average of 10\% (Hudson Valley Pattern for Progress [Pattern], 2020; U.S. Department of Agriculture, Food and Nutrition Service, n.d.). Following the onset of COVID-19, food banks across the region experienced demand increases ranging from $40 \%$ to $400 \%$, while unemployment applications increased by between 200\% and 400\% (Pattern, 2020). Simultaneously, disrupted supply chains forced farmers to destroy or dump surplus crops and milk (Yaffe-Bellany \& Corkery, 2020). This faltering ability to move supply and meet demand raised concerns and sparked interest in generating solutions.

The Food Bank of the Hudson Valley (FBHV) partnered with Food Systems Foresight (FSF), an advisory firm, to host an online FSDs event with a broad scope in June 2020. This event was followed by a second, more focused event in August 2020. Both events were designed using existing FSDs approaches as well as asset-based approaches used in nearby settings prior to the pandemic (Weissman \& 
Potteiger, 2018). The June event encouraged participants to use their collective knowledge as an asset to generate potential solutions in group settings. The August event encouraged participants to reflect individually on how they might leverage a broad range of existing assets, including technology, human resources, institutions, infrastructure, and collaboration capabilities to build a better future rather than fixate on current challenges. Participation from government and civil society organizations was ample, and while the business community had less fulsome representation, overall stakeholder diversity allowed for a holistic review of available assets.

\section{Results and Discussion}

The Hudson Valley Online FSDs highlighted systemic issues and key needs, including transdisciplinary communication and collaboration, food policy councils and alliances, and local food systems infrastructure (FSF \& FBHV, 2020). Assembling stakeholders from across systems disrupted the local norm of organizing into industry verticals, while connecting actors and prompting identification of common cross-sector issues. The participants quickly adapted to a systems mindset and were able to identify problems and solutions that were broad and systemic in nature.

The results indicated a keen awareness of barriers to working across industries and spotlighted needs relating to coordination and inclusive food governance. This echoed the findings of similar communityfocused food systems studies (Brouwer et al., 2020; FSF \& FBHV, 2020; Weismann \& Potteiger, 2018). Common themes also emerged within the global FSDs, such as the need for broad stakeholder involvement and inclusive innovation (FSF \& FBHV, 2020; Nabarro \& Alexander, 2019). The consistency between the global and local scale is encouraging and speaks to a degree of convergence of food systems priorities.

\section{Looking Forward}

The act of dialogue in Hudson Valley food systems will continue under the stewardship of a local community foundation that had identified food systems as a strategic investment area prior to the pandemic. The Hudson Valley Online FSDs documented here provide fodder for its future work, having served as an emergency reporting mechanism for the impact of COVID-19 on local food systems.

The use of dialogue as part of a food systems approach thus has demonstrated potential at the local level; however, it is not yet clear from this early-stage example how the insights and approaches generated will be operationalized. Additional research is required to understand the practical implications and attributable results of dialogue relating to food systems at the global level as well. Finally, future research is called for in the arena of food business engagement in these processes, which could have an outsized impact if done effectively.

\section{References}

Brouwer, I. D., McDermott, J., \& Ruben, R. (2020). Food systems everywhere: Improving relevance in practice. Global Food Security, 26, 1-10. https://doi.org/10.1016/j.gfs.2020.100398

Caron, P., Ferrero y de Loma-Osorio, G., Nabarro, D., Hainzelin, E., Guillou, M., Andersen, I., ... Verburg, G. (2018). Food systems for sustainable development: Proposals for a profound four-part transformation. Agronomy for Sustainable Development, 38(41), 1-12. https://doi.org/10.1007/s13593-018-0519-1

Food Systems Foresight \& Food Bank of the Hudson Valley. (2020). Online food systems dialogues New York's Hudson Valley Region summary report. Retrieved from Food Systems Dialogues website: https://foodsystemsdialogues.org/ind_fsds_200617_hudson-valley_summary-report_uploaded/

Hansen, A. R., Ingram, J. S. I., \& Midgley, G. (2020). Negotiating food systems resilience. Nature Food, 1, 519. https://doi.org/10.1038/s43016-020-00147-y 
High Level Panel of Experts [HLPE]. (2020). Impact of COVID-19 on food security and nutrition. Retrieved from the Food and Agriculture Organization of the United Nations website: http://www.fao.org/fileadmin/templates/cfs/Docs1920/HLPE 2020/New HLPE paper COVID EN.pdf

Hudson Valley CSA Coalition. (n.d.). Find a farm. Retrieved September 2020 from https://hudsonvalleycsa.org/find-a-farm/

Hudson Valley Pattern for Progress. (2020, May). Vulnerability revealed - COVID-19 and the Hudson V alley food system. Retrieved from https://www.pattern-for-progress.org/wp-content/uploads/2020/05/Food-VulnerabilityRevealed-5.18.20-Absolute-Final.pdf

Ingram, J. (2011). A food systems approach to researching food security and its interactions with global environmental change. Food Security, 3, 417-431. https://doi.org/10.1007/s12571-011-0149-9

Lawrence, M. A., Baker, P. I., Pulker, C. E., \& Pollard, C. M. (2019). Sustainable, resilient food systems for healthy diets: The transformation agenda. Public Health Nutrition, 22(16), 2916-2920. https://doi.org/10.1017/S1368980019003112

Nabarro, D., \& Alexander, N. (2019). The food systems dialogues: Emerging themes 2018-19. Retrieved from The Food Systems Dialogues website: https://foodsystemsdialogues.org/wp-content/uploads/2020/04/191218 Red-Thread-themes-synthesis.pdf

Rosenzweig, C., Mbow, C., Barioni, L. G., Benton, T. G., Herrero, M., Krishnapillai, M., .. \& Portugal Pereira, J. (2020). Climate change responses benefit from a global food system approach. Nature Food, 1, 94-97. https://doi.org/10.1038/s43016-020-0031-z

U.S. Department of Agriculture, Food and Nutrition Service [USDA FNS]. (n.d.). SNAP data tables. Retrieved September 2020 from https://www.fns.usda.gov/pd/supplemental-nutrition-assistance-program-snap

van Berkum, S., Dengerink, J., \& Ruben, R. (2018). The food systems approach: Sustainable solutions for a sufficient supply of healtby food (No. 2018-064). Wageningen Economic Research. https://doi.org/10.18174/451505

Weissman, E., \& Potteiger, M. (2018). Collaboration and diverse stakeholder participation in food system planning: A case study from Central New York. Renewable Agriculture and Food Systems, 35(2), 115-119. https://doi.org/10.1017/S1742170518000431

Yaffe-Bellany, D., \& Corkery, M. (2020, April 11). Dumped milk, smashed eggs, plowed vegetables: Food waste of the pandemic. The New York Times. Retrieved from https://www.nytimes.com/2020/04/11/business/coronavirus-destroying-food.html 